Int. J. Dev. Biol. 58: 355-362 (2014)

doi: $10.1387 /$ ijdb.140106ja

\title{
Expression and evolution of the Tiki1 and Tiki2 genes in vertebrates
}

\author{
ALICE H. REIS\#,1, BRYAN T. MACDONALD",2, KERSTIN FEISTEL ${ }^{3}$, JOSE M. BRITO ${ }^{1}$, NATHALIA G. AMADO ${ }^{1}$, \\ CHIWEI XU², JOSE G. ABREU*,1 and XI HE*,2 \\ ${ }^{1}$ Instituto de Ciências Biomédicas, Universidade Federal do Rio de Janeiro, Rio de Janeiro, Brazil, \\ ${ }^{2}$ F. M. Kirby Center, Boston Children's Hospital, Harvard Medical School, Boston, MA, USA and \\ ${ }^{3}$ Institute of Zoology, University of Hohenheim, Stuttgart, Germany
}

\begin{abstract}
Tiki1 is a Wnt protease and antagonist specifically expressed in the Spemann-Mangold Organizer and is required for head formation in Xenopus embryos. Here we report neighbor-joining phylogenetic analysis of vertebrate Tiki genes and their mRNA expression patterns in chick, mouse, and rabbit embryos. Tiki1 and Tiki2 orthologues are highly conserved, and exhibit similar but also different developmental expression patterns among the vertebrate/mammalian species analyzed. The Tiki1 gene is noticeably absent in the rodent lineage, but is present in lagomorphs and all other vertebrate/mammalian species examined. Expression in Hensen's node, the equivalent of the Xenopus Organizer, was observed for Chick Tiki2 and Rabbit Tiki1 and Tiki2. Mouse Tiki2 was detected at low levels at gastrulation and head fold stages, but not in the node. Mouse Tiki2 and chick Tiki1 display similar expression in the dorsal spinal cord. Chick Tiki1 expression was also detected in the surface ectoderm and maxillary bud, while chick Tiki2 was found in the anterior intestinal portal, head mesenchyme and primitive atrium. Our expression analyses provide evidence that Tiki1 and Tiki2 are evolutionarily conserved among vertebrate species and their expression in the Organizer and other regions suggests contributions of these Wnt inhibitors to embryonic patterning, as well as organogenesis. Our analyses further reveal mis-regulation of TIKI1 and TIKI2 in human cancer and diseases.
\end{abstract}

KEY WORDS: Tiki1, Tiki2, Wnt, organizer, head induction, organogenesis

The Wnt signaling pathway plays central roles in a multitude of biological processes, including embryogenesis, tissue homeostasis, and regeneration, and its perturbation causes degenerative diseases, birth defects and cancer (Clevers and Nusse, 2012, MacDonald et al., 2009). In addition to the existence of a large family of the secreted Wnt ligands, Wnt signaling is also controlled by several families of secreted and membrane-tethered Wnt modulators, which individually or in concert regulate the Wnt pathway activity spatially and temporarily as best exemplified during anterio-posterior (AP) patterning in early vertebrate embryogenesis (Cruciat and Niehrs, 2013). During gastrulation of Xenopusembryos, high Wnt activity promotes posterior patterning whereas low or no Wnt activity is required for anterior head formation (MacDonald et al., 2009, Niehrs, 2004, Petersen and Reddien, 2009). Precise regulation is achieved by several classes of Wnt antagonists that are specifically expressed in the Spemann-Mangold organizer and its descendent tissues in the anterior anlagen, including secreted Frizzled-related proteins (sFRPs), cerberus, Dickkopf-1 (Dkk1), and Tiki1 (De Robertis and Kuroda, 2004, Niehrs, 2004, Zhang et al., 2012). Anterior inhibition of the Wnt pathway is essential for establishing AP patterning throughout vertebrate species, although the complement of Wnt antagonists expressed in the Organizer may differ among species (Niehrs, 2004).

Tiki1 is the newest Wnt antagonist identified that is specifically expressed in the Organizer and the descendent prechordal mesendoderm, and is required for head development in Xenopus embryos (Zhang et al., 2012). Tiki1, and its paralogue Tiki2, are

Abbreviations used in this paper: sFRP, frizzled-related protein; Dkk1, Dickkopf-1.

\footnotetext{
*Address correspondence to: Jose G Abreu. Instituto de Ciências Biomédicas, Universidade Federal do Rio de Janeiro, Rio de Janeiro, 21949-590, Brazil. e-mail: garciajr@icb.ufrj.br or Xi He. F. M. Kirby Center, Boston Children's Hospital, Harvard Medical School, Boston, MA 02115, USA. e-mail: xi.he@childrens.harvard.edu - \#Note: Both authors contributed equally to this paper.
}

Supplementary Material (2 figures, 1 table) for this paper is available at: http://dx.doi.org/10.1387/ijdb.140106ja

Accepted: 16 July 2014. Final, author-corrected PDF published online: 30 September 2014.

ISSN: Online 1696-3547, Print 0214-6282

(C) 2014 UBC Press

Printed in Spain 
found in most vertebrates and encode metalloproteases that cleave Wnt proteins at the amino terminus thereby inactivating Wnt morphogens (Zhang et al., 2012). Wnt inactivation by Tiki reveals an exquisite regulatory system that acts in both Wnt-secreting and Wnt-responding cells (Zhang et al., 2012). Considering Tiki1 expression and function during Xenopus embryogenesis and the broader role of Wnt signaling in AP patterning in vertebrates, we identified and performed evolutionary sequence analysis of Tiki1 and Tiki2 in vertebrate/mammalian species, and carried out comparative in situ hybridization of Tiki1 and Tiki2 in avian, rabbit and mouse embryos. Our results show an early anterior Tiki gene expression in the vertebrate/mammalian organizer suggesting a conserved role in AP patterning, with the exception of the rodent lineage, which has lost the Tiki1 gene.

\section{Results}

\section{Evolutionary conservation of Tiki1 and Tiki2 among vertebrates}

Phylogenetic analysis using TIKI protein sequences was performed using a Neighbor-Joining method, which is suitable for reconstructing phylogenetic trees using evolutionary distance data. This method has advantages in that it is fast and thus suited for large datasets and bootstrap analysis, and permits delineation of lineages with different branch lengths and correction for multiple substitutions (Saitou and Nei, 1987). Our phylogenetic analyses revealed that Tiki proteins are highly conserved among vertebrate species (Supplementary Fig. S1). All species analyzed have both Tiki1 and Tiki2 genes, except for Rodentia, which appear to have lost Tiki1 (Fig. 1A). The Tiki1 gene spans seven exons in the human and rabbit genomes (Fig. S2). Remnants of the ancient Tiki1

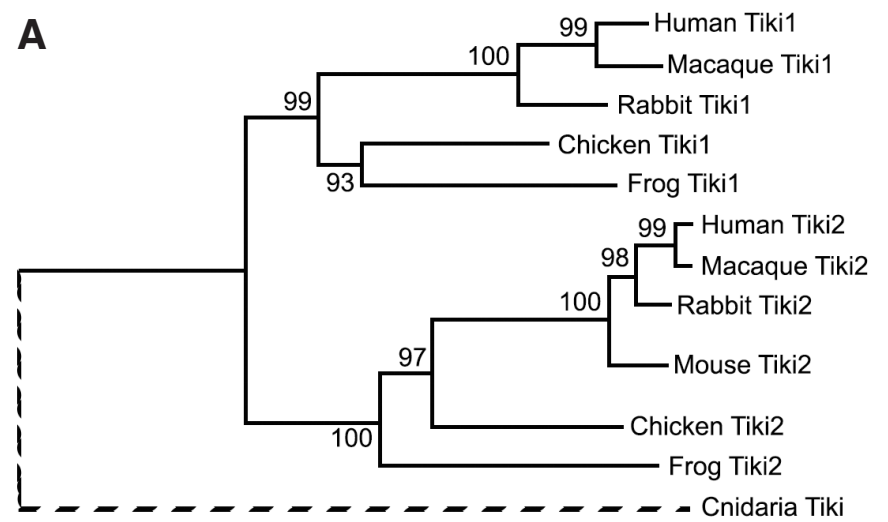

\section{B 0.05}

gene could be detected in the rodent genomes (mouse, rat, guinea pig and squirrel) in a region that is syntenic with the Tiki1 locus in human and rabbits; however the residual exon fragments no longer encode a full-length Tiki1 protein (Fig. S2). Curiously, the group most closely related to Rodentia, the Lagomorpha (rabbit), has Tiki1 and Tiki2, suggesting that this loss has occurred exclusively in Rodentia. In addition to the common rabbit (Oryctolagus cuniculus), supporting evidence for the presence of Tiki1 and Tiki2 in Lagomorpha is also found in the draft genome sequence of the Pika rock rabbit (Ochotona princeps) (data not shown).

Human TIKI1 displays lower sequence identity (numbers in red) with its mammalian orthologs (red) compared to that of human TIKI2 with its orthologs (Fig. 1B). Surprisingly Chicken and Xenopus Tiki1 proteins are more similar (green) and thus grouped together compared to the orthologous Chicken and Xenopus Tiki2 (Fig. 1B), possibly reflecting an evolutionary gap as a result of the loss of the Tiki1 gene in rodents. Given the loss of Tiki1 in Rodentia, which shared the last common ancestor with humans -90MYA, we analyzed the orthologous conservation of Tiki1 and Tiki2 within mammals. A pair-wise comparison between TIKIgenes from Human, Macaque, and Rabbit show that TIKI2 exhibits higher orthologous (interspecies) conservation than TIKI1 (Fig. S1). The greater divergence in mammalian Tiki 1 proteins and the loss of Tiki 1 in the rodent lineage suggests that Tiki2 may be under stronger selective pressure than Tiki1 during mammalian evolution.

\section{Expression of Tiki genes during chick development}

The chick embryo develops as a bilayer blastodisc with an epiblast and underlying hypoblast in a manner similar to embryogenesis of humans and most mammals (Solnica-Krezel and Sepich, 2012, Viebahn, 1999). The expression pattern of Tiki1 and Tiki2 was examined in chick embryos from $\mathrm{HH} 4$ to $\mathrm{E} 3(\mathrm{HH} 20-21)$. The earliest stage we detected Tiki1 expression is at $\mathrm{HH} 4$ (Fig. 2A). Tiki1 is expressed within embryonic tissues in the area pellucida/ area opaca boundary, in the anterior, lateral and posterior regions of the area pellucida (Fig. 2A, arrows). Cross section images show that Tiki1 mRNA is present in both epiblast and hypoblast (Fig. 2A'; asterisks). At HH5 a diffuse and ubiquitous expression of Tiki1 was faintly detected (Fig. 2B). Later on at the 3 somite stage (ss; HH8) we did not detect any significant Tiki1 expression (Fig. $2 \mathrm{C}$ and D). At the 6ss Tiki1 becomes detectable in the cephalic region and lateral to Hensen's node (Fig. 2E). Its expression was specifically found in the surface ectoderm and at the lateral plate mesoderm of the pericardial portion of the pleural-peritoneal cavity (Fig. 2E, E'). The neural tube, notochord, mesenchyme and pharyngeal endoderm were negative for Tiki1 expression (Fig. 2E'). At E2

\begin{tabular}{|c|c|c|c|c|c|}
\hline & Human Tiki1 & Macaque Tiki1 & Rabbit Tiki1 & Chicken Tiki1 & Xenopus Tiki1 \\
\hline Human Tiki1 & $\star \star \star \star$ & 94.1 & 86.7 & 68.3 & 65.5 \\
\hline Macaque Tiki1 & & 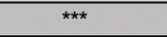 & 86.3 & 67.9 & 64.5 \\
\hline Rabbit Tiki1 & & & 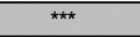 & 69.3 & 66.1 \\
\hline Chicken Tiki1 & & & & 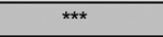 & 74.5 \\
\hline Xenopus Tiki 1 & & & & & $\star \star \star *$ \\
\hline
\end{tabular}

\begin{tabular}{|c|c|c|c|c|c|}
\hline & Human Tiki2 & Macaque Tiki2 & Rabbit Tiki2 & Chicken Tiki2 & Xenopus Tiki2 \\
\hline Human Tiki2 & $\star \star \star *$ & 97.9 & 92.2 & 72.3 & 65.7 \\
\hline Macaque Tiki2 & & $\star \star \star$ & 92.1 & 72.1 & 65.3 \\
\hline Rabbit Tiki2 & & & 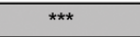 & 73.0 & 67.4 \\
\hline Chicken Tiki2 & & & & 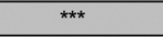 & 70.5 \\
\hline Xenopus Tiki2 & & & & & $\star \star \star$ \\
\hline
\end{tabular}

Fig. 1. Evolutionary comparisons of vertebrate Tiki proteins. (A) Phylogenetic tree showing homology among Tiki proteins from Human, Macaque, Mouse, Rabbit, Chicken and Xenopus based on Neighbor-Joining phylogenetic methods. Distances in the cladogram are derived from amino acid substitutions. The full length protein sequences are shown in supplementary Fig. S1. Tiki1 is absent from the mouse and all sequenced rodents (see Fig. S2B). CnidarianTiki protein is used as an out-group. (B) Orthologous comparisons ofTiki1 andTiki2 proteins in percent identity using ClustalW alignment. 

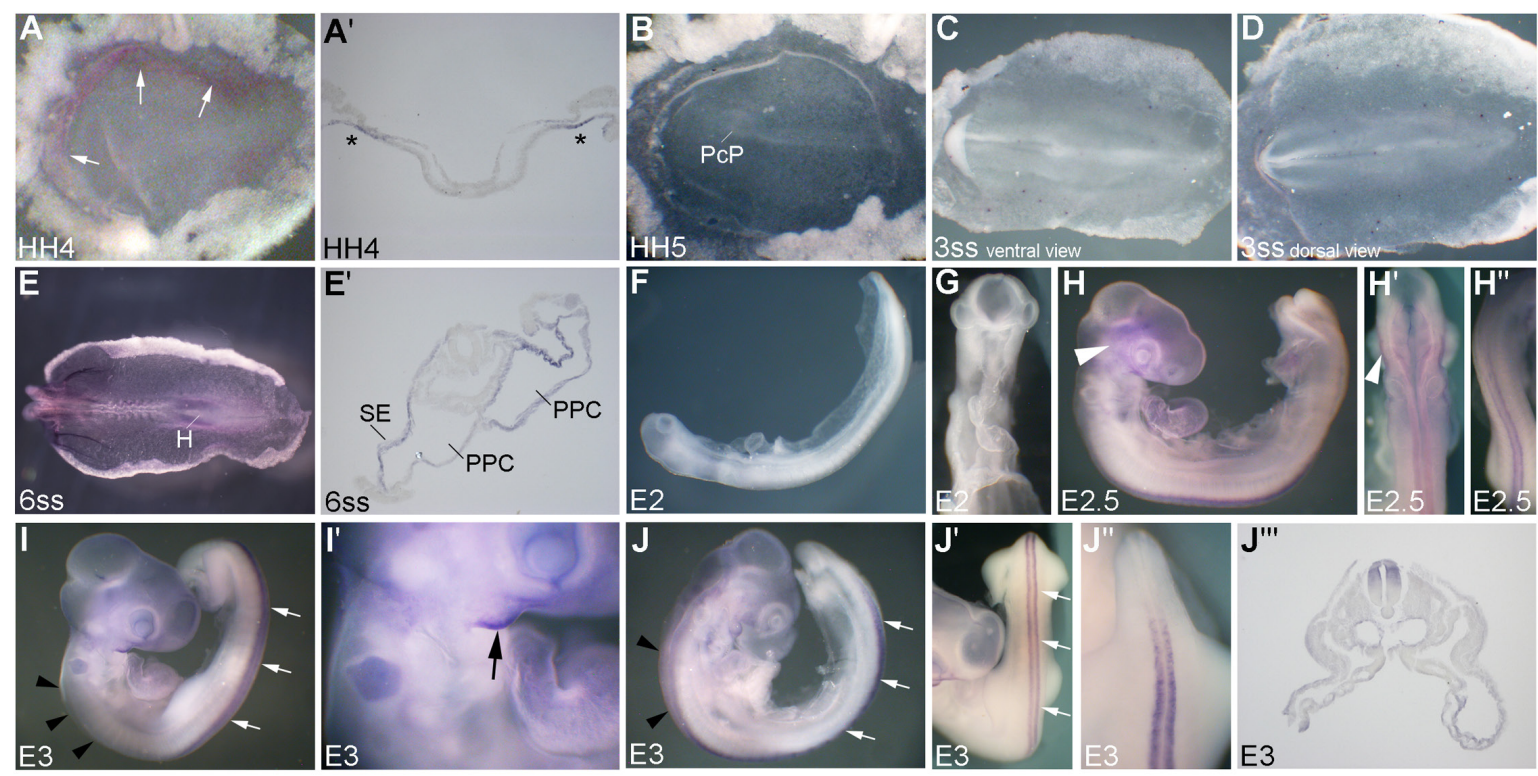

Fig. 2. In situ hybridization analysis of Tiki1 during chick embryonic development. Tiki1 transcripts were analyzed byin situ hybridization in whole mountorcross sections at stage $\mathrm{HH} 4$ (A); white arrows indicate expression in the anterior, lateral and posterior area pellucida. (A') Asterisks mark expression in the epiblastand hypoblast). HH5 (B), the 3-somite stage (ss); (C,D) ventral and dorsal views, respectively; the 6ss $\left(\mathbf{E}, \mathbf{E}^{\prime}\right), E 2(\mathbf{F}, \mathbf{G})$ lateral and head ventral views respectively), E2.5 (H, $\left.\mathbf{H}^{\prime}, \mathbf{H}^{\prime \prime}\right)$; arrowhead indicates lateral forehead ectoderm. E3 (I, $\left.\mathbf{I}^{\prime}, \mathbf{J}, \mathbf{J}^{\prime}, \mathbf{J}^{\prime \prime}\right)$; the black arrow and arrowheads indicate the maxilar bud and anterior neural tube, respectively, and the white arrows mark the posterior neural tube). A posterior cross section at E3 is shown ( ('"'). Abbreviations: PCP, prechordal plate; H, Hensen's node; SE, surface ectoderm; PPC, pleural-peritoneal cavity.

(embryonic day 2) no expression of Tiki1 was detected (Fig. 2F and G). However, from E2.5 Tiki1 transcripts were found in the lateral forehead ectoderm (Fig. $2 \mathrm{H}$ arrowhead) and in the dorsal neural tube from the myelencephalon to more posterior regions (Fig. 2 H' and H'). At E3 Tiki1 expression could be detected in the ectoderm of the maxillary bud (Fig. 2I, l'; black arrow). The expression is maintained in the neural tube along the trunk axis (Fig. 2l, $\mathrm{J}$ and $\mathrm{J}$ '; white arrows), but not in the cervical and more anterior regions (Fig. 2 I and J, black arrowheads). Moreover, Tiki1 is not expressed in the caudal neural tube posterior to the hind limb bud (Fig. 2J"). Tiki1 expression is restricted to the dorsal part of neural tube as observed in cross sections of the trunk region of an E3 chick embryo (Fig. 2J'"). Tiki2 mRNA was observed in the germinal crescent (Fig. 3A, arrows) and in Hensen's node of the HH4 chick embryo (Fig. 3A). Interestingly, at HH5 Tiki2 is expressed in the prechordal plate $(\mathrm{PcP})$ and the endoderm but not the ectoderm (Fig. 3 B,B'). In the endoderm Tiki2 expression is medial though not extended laterally (Figure 3B', arrowhead). Tiki2 is expressed in Hensen's node, PcP and medial endoderm (Fig. 3B'). At the 4ss Tiki2 mRNA was detected throughout the cephalic region, and in the anterior intestinal portal (AIP) of the foregut (Fig. $3 \mathrm{C}$ and $\mathrm{C}^{\prime}$ ). At the 5ss Tiki2 is expressed laterally and ventrally to the anterior neural tube (Fig. 3 D,D'). At 7ss Tiki2 was detected in the head mesenchyme but not in the ectoderm and neural tube, although we observed a slight expression in the neural ectodermal ridge (Fig. 3E black arrow). Tiki2 expression persists at the 9ss and was detected ubiquitously in the cephalic region up to AIP (Fig. 3F). In order to describe Tiki2 expression more precisely, cross sections in the cephalic region were examined along the AP axis (Fig. 3F, dashed lines). In the mesencephalic region Tiki2 mRNA was observed in the head mesenchyme (white arrow), in the pharyngeal endoderm (En) and lateral/ventral ectoderm (asterisks; Fig. 3F'). At the level of the anterior rhombencephalon, Tiki2 expression was detected in the paraxial mesoderm (empty arrows), lateral plate mesoderm (empty arrowheads), pharyngeal endoderm (En), and lateral/ventral ectoderm (asterisks) (Fig. 3F"). In the posterior rhombencephalon at the otic vesicle level, Tiki2 expression was detected in the lateral plate mesoderm (empty arrowheads) and pharyngeal endoderm (En) (Fig. 3F"'). In more posterior cross sections Tiki2 mRNA is expressed in the lateral plate mesoderm, the adjacent endoderm and the dorsal endoderm (Fig. 3F'"', arrows). We did not detect any Tiki2 expression in the somites during our analysis (Fig. 3F'"'). At E2 Tiki2 was detected at the AIP and primitive atrium (Fig. 3G, G'). At E3.5 Tiki2 mRNA is restricted to the ectoderm dorsal and lateral to the neural tube and in lateral mesoderm between somites (Fig. 3H, I and I'; arrowheads).

\section{Tiki1 and Tiki2 expression during early rabbit development}

We next examined the expression pattern of Tiki1 and Tiki2 by whole-mount in situhybridization in rabbit embryos during gastrulation and neurulation. Rabbit embryos are flat and disc-shaped and resemble human embryonic development more closely than do mouse embryos, which develop via an inverted cup-shaped "egg cylinder" instead of a flat blastodisc (Solnica-Krezel and Sepich, 2012, Viebahn, 1999). At about day 7.5 post coitum, formation of Hensen's node (the equivalent of Spemann's Organizer) at the rostral end of the elongated primitive streak is the landmark of gastrulation stage 4. At this time, implantation events are initiated (Idkowiak et al., 2004).

Tiki1 was first detected when Hensen's node appears at the tip of the primitive streak at stage 4- (Fig. 4A). At this stage, Tiki1 expression is restricted to cells of the hypoblast layer. This expression is localized to an anterior crescent-shaped domain from which faint staining fans out posteriorly (Fig. 4A'). Additionally, Tiki1 is expressed in the hypoblast underlying Hensen's node and its periphery (Fig. 4A"). At stage 4+, when the primitive streak is fully elongated, the crescent-shaped domain of Tiki1 vanishes while its expression becomes restricted to an area encircling Hensen's node (Fig. 4B). Concomitant with the elongation of the notochordal process and emergence of the notochordal plate at stage 5 , circular 

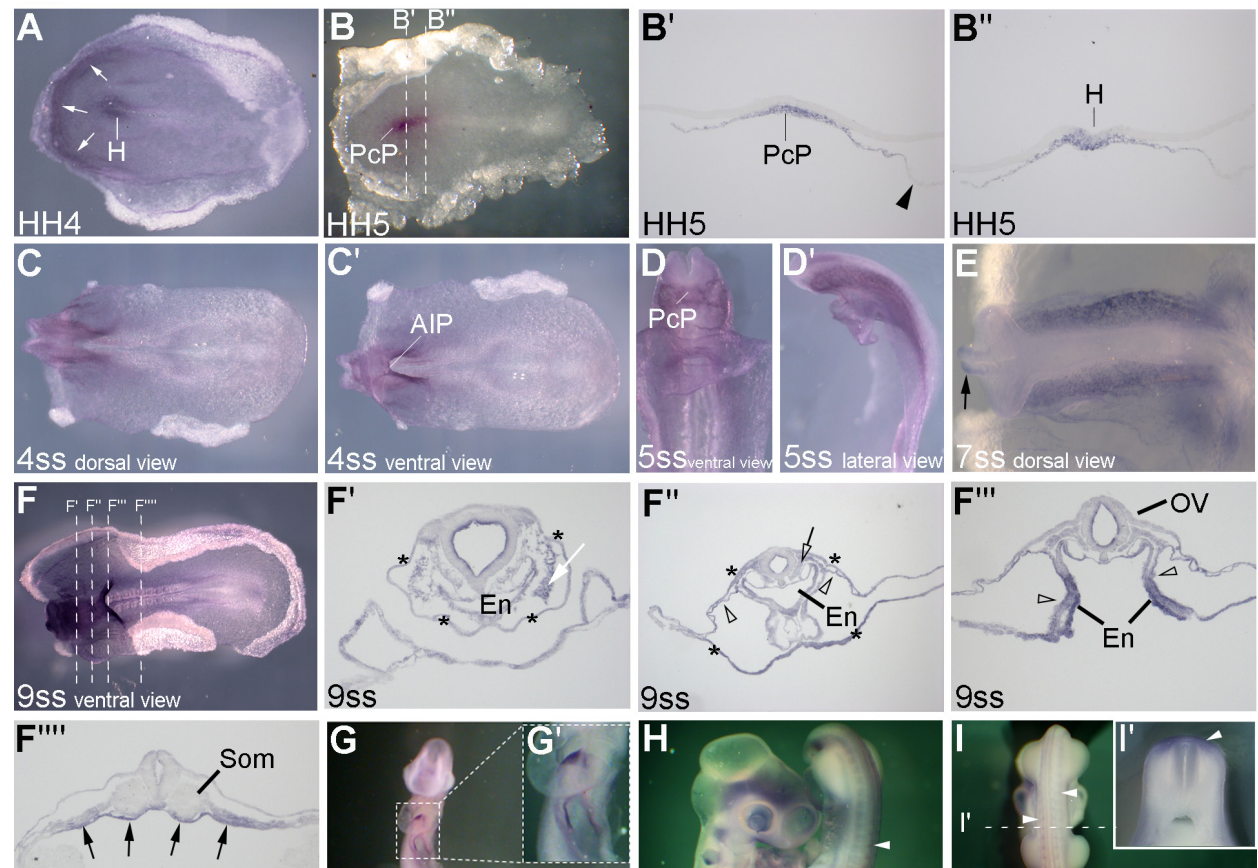

9ss
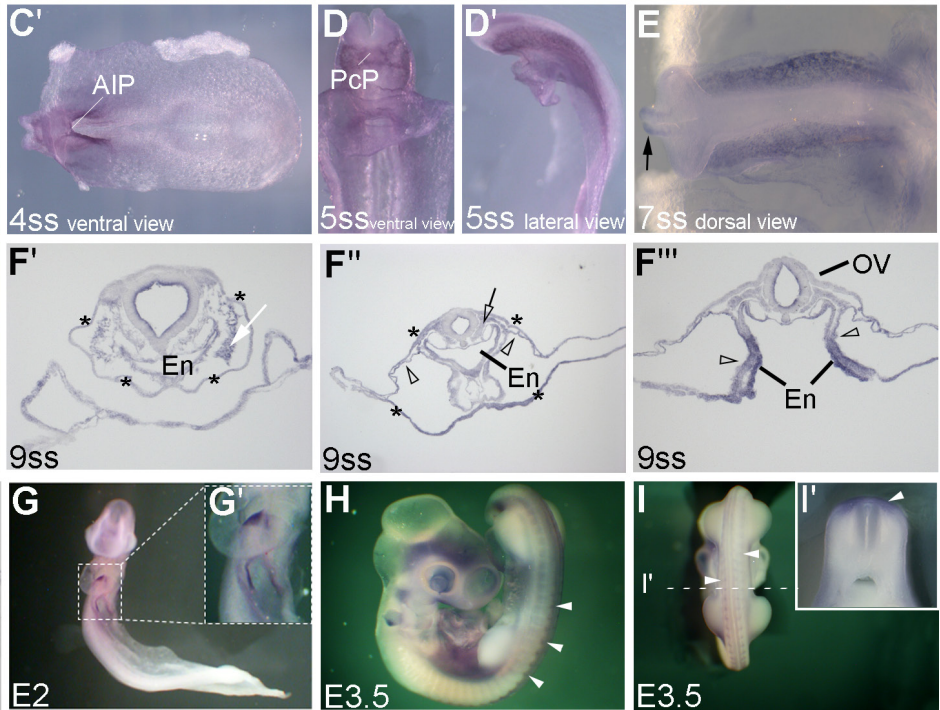

9ss

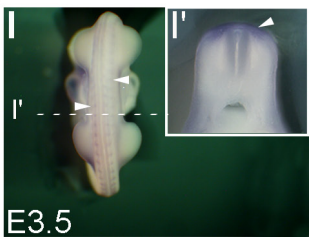

expression of Tiki1 around Hensen's node becomes elongated and expanded along the AP axis (Fig. 4C), and Tiki1 was detected in the PcP region (Fig. 4C') as well as in endodermal tissue flanking the notochordal plate on either side (Fig. 4C"). At stage 6, Tiki1 expression had ceased in cells bordering the notochordal plate (Fig. 4D). Instead, the entire endoderm of the posterior half of the embryo now expresses Tiki1 (Fig. 4D'). During somitogenesis, Tiki1 expression appears in the developing heart, such that at the four somite stage, transcripts are found in endodermal cells all along the crescent-shaped heart anlage (Fig. 4 E,E'). For the first time, Tiki1 is also expressed in cells other than hypoblast/endoderm, as it appears in both primitive streak and presomitic mesoderm (Fig. 4E"). Expression of Tiki2 becomes

A

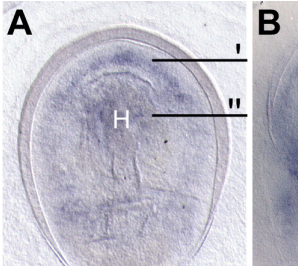

B
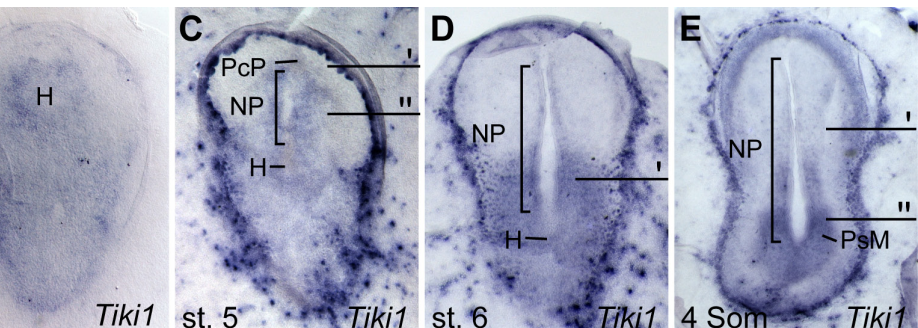

st. $4 \quad$ Tiki1 st. 4

$\mathbf{F}$

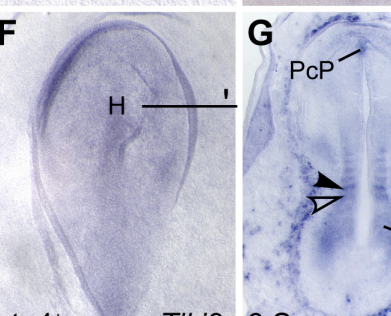

st. $4^{+} \quad$ Tiki2 6 Som
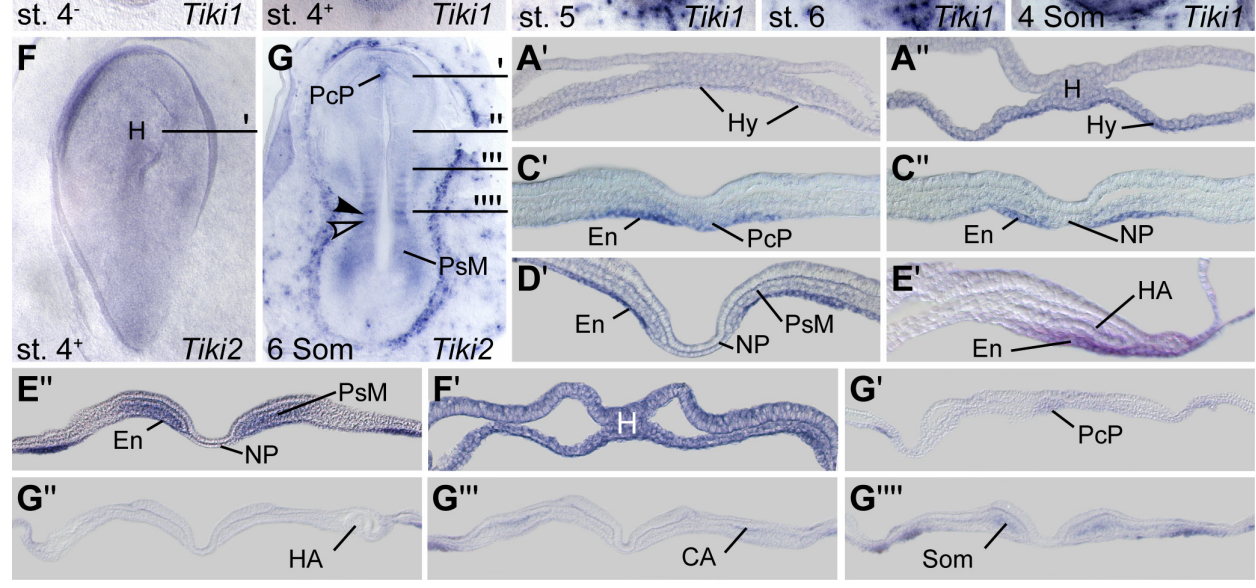

$-N P$
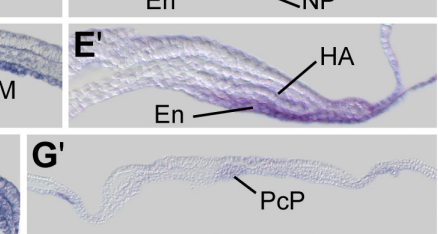

G"

$\mathrm{HA}$

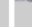

Fig. 3. In situ hybridization analysis of Tiki2 during chick embryonic development. Tiki2 transcripts were analyzed by in situ hybridization in whole mount or cross sections at stages $\mathrm{HH} 4$ (A); arrows indicate the germinal crescent; HH5 (B), HH5 sectioning at the level of prechordal plate ( $\left.\mathbf{B}^{\prime}\right)$; the black arrowhead indicates the lateral endoderm; and Hensen's node (B"), the 4ss (C,D), with dorsal and ventral views respectively, and (C'), ventral view; the 5ss (D, $\mathbf{D}^{\prime}$, ventral and lateral views, respectively); the 7ss (E) black arrow indicates the neural ectodermal ridge); the 9SS (E); ventral view, white dashed lines indicate the level of the cross sections; the 9ss cross sections ( $\left.\mathbf{F}^{\prime}, \mathbf{F}^{\prime \prime}, \mathbf{F}^{\prime \prime \prime}, \mathbf{F}^{\prime \prime \prime \prime}\right)$ white arrow, the head mesenchyme; asterisk, the laterall ventral ectoderm; empty arrow, paraxial mesoderm; empty arrowhead, the lateral plate mesoderm; black arrow, dorsal and lateral endoderm; E2 $\left(\mathbf{G}, \mathbf{G}^{\prime}\right)$ E3.5 (H), lateral view, (I), dorsal view, (I'), cross section at the level of the trunk indicated by the dashed lines; white arrowheads indicate expression in the ectoderm dorsal and lateral to the neural tube at the trunk. Abbreviations: H, Hensen's node; PCP, prechordal plate; AIP, anterior intestinal portal; En, endoderm; Som, somite; and OV, the otic vesicle.

Fig. 4 (Left, bottom). In situ hybridization analysis of Tiki1 and Tiki2 during early rabbit embryonic development. Wholemount in situ hybridization of rabbit embryos of defined stages (st.) using antisense probes specific for rabbit Tiki1 (A-E) and Tiki2 (F,G) Rabbit embryos were staged according to Blum et al., (2007). Specimens are shown in ventral views with anterior to the top. Histological sections ( $A^{\prime}$ - $\left.G^{\prime \prime}\right)$ in ( $\left.\mathbf{A}, \mathbf{C}-\mathbf{G}\right)$ are shown dorsal side to the top. (A, $\left.\mathbf{A}^{\prime}, \mathbf{A}^{\prime}\right)$ Expression in hypoblast (Hy) cells in an anterior crescentshaped domain and underlying Hensen's node $(H)$ in a st. 4 embryo. (B) Expression around the area of Hensen's node in a st. $4^{+}$ embryo. (C, C', C") Rostro-caudally-expanding expression in the endoderm (En), expression in the prechordal plate $(P C P)$ bordering the developing notochordal plate (NP) in a st. 5 embryo. (D, D') Expression in endodermal cells of the posterior half of a st. 6 embryo. The presomitic mesoderm (PsM) was devoid of Tiki1 transcripts. (E, E', E") Tiki1 expression emerged in the endoderm underlying the caudal aspect of the heart anlage (HA), in the presomitic mesoderm and underlying endoderm in a 4 somite (Som) stage embryo. (F,F') Tiki2 was expressed ubiquitously before somitogenesis. (G, G', G", G'"', G'"') Expression of Tiki2 in the prechordal plate, presomitic mesoderm and the compacting (emptyarrowhead) and compacted (arrowhead) somites. Note the absence of expression in the heart anlage and emerging expression in the coelom anlage (CA). 
apparent at stage 4+, when transcripts are distributed uniformly in all three germ layers all across the embryonic blastodisc (Fig. 4 F,F'). A localized pattern of Tiki2 emerges during somitogenesis (Fig. 4G). In embryos at the six somite stage, anterior-most expression of Tiki2 is found in mesendodermal cells of the prechordal plate (Fig. 4G'). Transcripts are absent from the heart (Fig. 4G”), however, cells of the intermediate mesoderm, caudally abutting the heart anlage, expressed Tiki2 (Fig. 4G'"). A conspicuous pattern of Tiki2 is present in presomitic and somitic mesoderm, with highest expression of Tiki2 in the latest formed (black arrowhead in Fig. 4G; Fig. 4G"'”) and slightly lower in the currently condensing somite (outlined arrowhead in Fig. 4G).

\section{Tiki2 expression during mouse development}

As aforementioned all sequenced vertebrate and mammalian (including human) genomes contain two Tiki genes, with the only exception of rodents, which do not have Tiki1 (Fig. 1). One speculation is that Tiki1 was selectively lost in the rodent lineage during evolution correlating, in part, with its unique early development as an inverted egg cylinder rather than a hypoblastic disc as in humans and other mammals (Arkell and Tam, 2012, SolnicaKrezel and Sepich, 2012, Viebahn, 1999). Following the loss of the rodent Tiki1 gene (after the Lagomorph/Rodent divergence 60 MYA) (Benton and Donoghue, 2007) it is possible that novel expression patterns of Tiki2 may have evolved to compensate for Tiki1 function. Therefore we examined the expression of Tiki2 during early and mid gestational development in mice. Tiki2 expression is absent from pre-streak embryos (Fig. 5A) and during the early phase of gastrulation (Fig. 5B). Tiki2 was first detected in the extraembryonic tissues following the closure of the amnion (Fig. 5C), followed by a broad anterior expression prominent at the neural folds (Fig. 5D-F). Mouse Tiki2 was present in the early heart anlagen before fusion of the right and left primitive aortae (Fig. 5F) and outflow tracts (Fig. 5 G and G'). Expression in the developing heart persisted as the highest Tiki2 expression domain from E8.0 until embryo turning and neural tube closure (Fig. 5 G-I). Rings of Tiki2 expression were detected later in development (Fig. 5 L-M). Tiki2 is also highly expressed in the PcP (Fig. 5H'). A dorsal stripe of Tiki2 expression was observed from the rostral prosencephalon to the rhombencephalon (Fig. $5 \mathrm{~J}-\mathrm{M}$ ). Prosencephalon expression of Tiki2 became more elaborate at the olfactory placode (Fig. 5L-M). Tiki2 was absent from the limb buds during the stages we examined, however Tiki2 was expressed along the lateral plate mesoderm between the fore and hind limb buds (Fig. 5N). Tiki2 displayed an
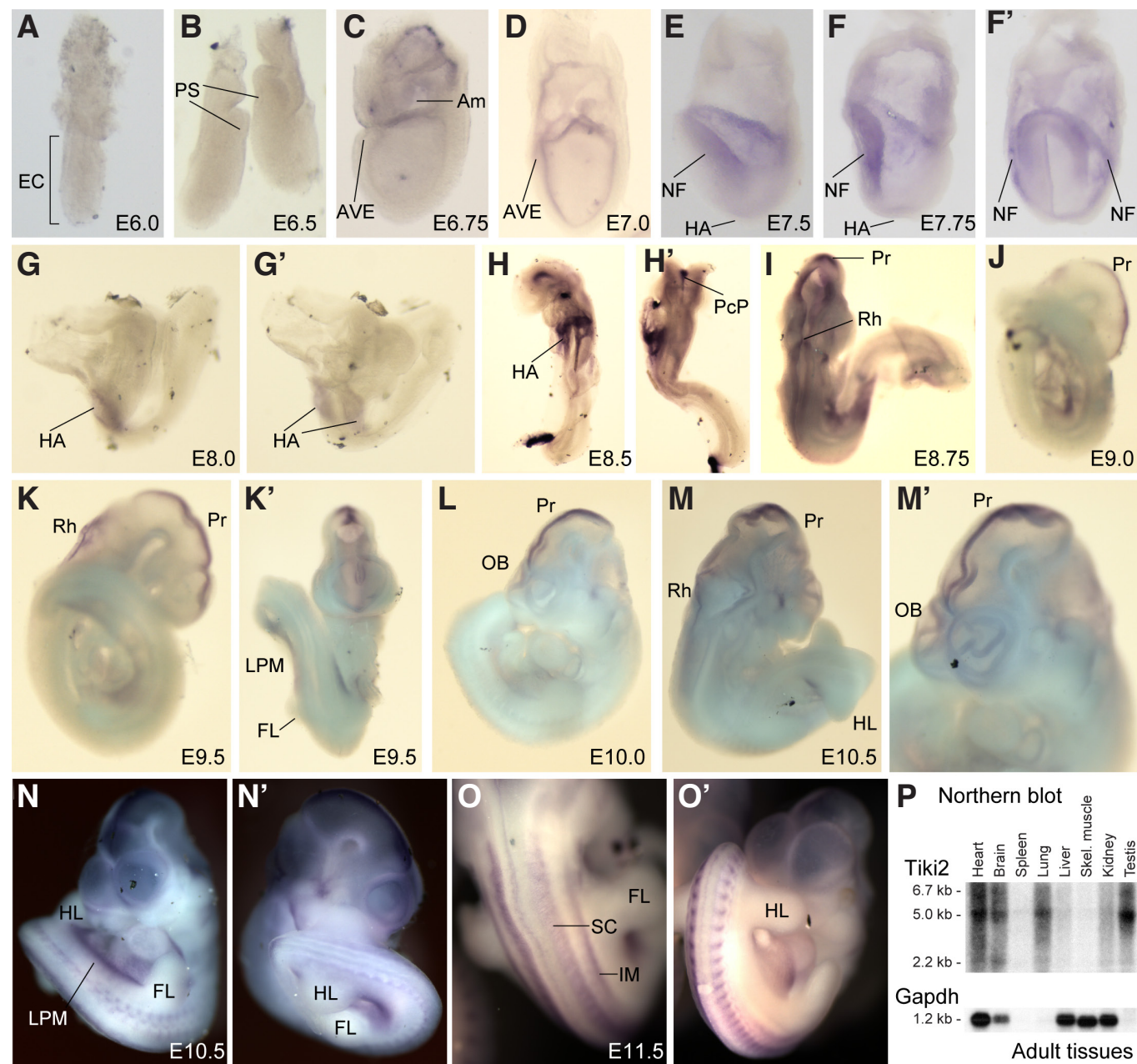
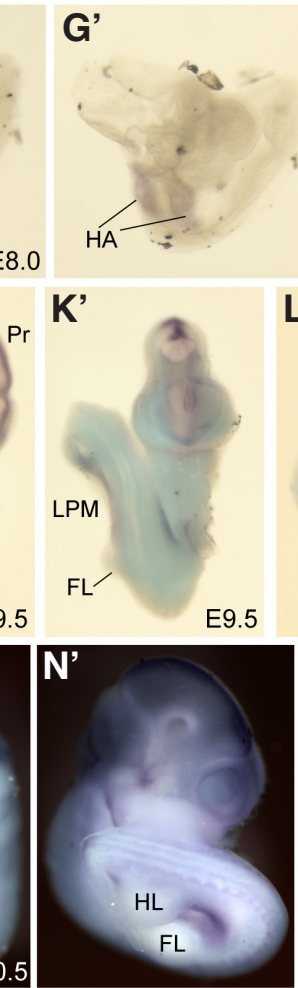
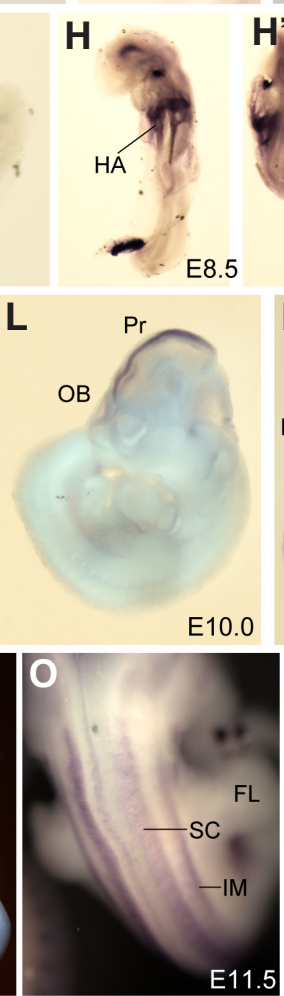
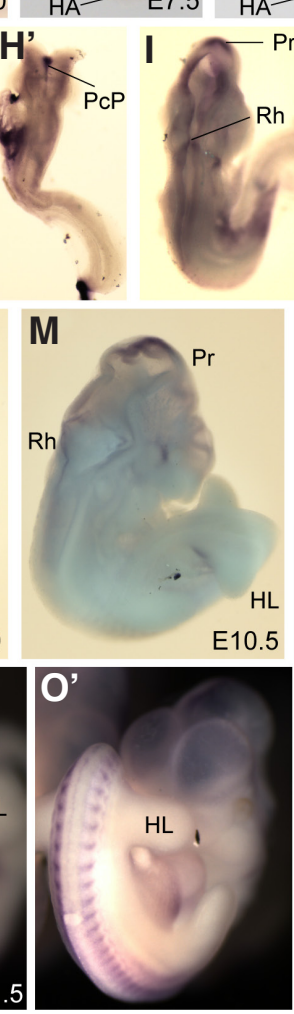
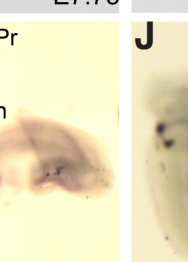

E8.75
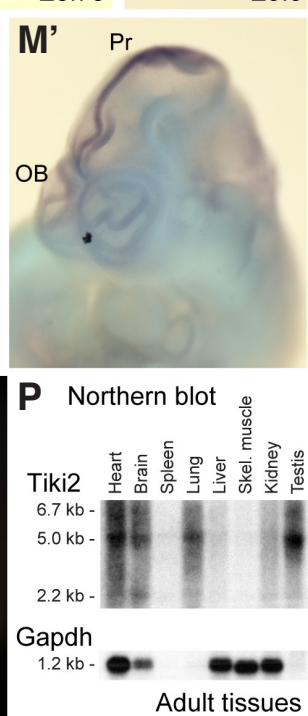

Fig. 5. Expression of Tiki2 during mouse embryonic development. (A-O) Whole-mount in situ hybridization of mouse embryos of defined stages using antisense probes specific for mouse Tiki2. (A,B) Tiki2 expression is absent in the egg cylinder (EC) and primitive streak (PS) stages. (C) Tiki2 was first detected in the extraembryonic tissues after closure of the amnion (Am) and was notably absent from the anterior visceral endoderm (AVE) region. (D) Tiki2 is diffusely expressed in the embryo proper at E7.0. (E,F) Distinct Tiki2 expression domains in the neural folds (NF) and heart anlage (HA) were found at E7.5 and E7.75, shown with the anterior facing left or $\left(\mathbf{F}^{\prime}\right)$ as an anterior view of the embryo. (G, G', H, $\mathbf{H}^{\prime}$ ) Tiki2 is expressed in the right and left fields of the heart anlage at E8.0 and E8.5, and was found in the prechordal plate $(P C P)$ at E8.5 as the embryo begins to turn. (I) Neural fold Tiki2 expression was detected during neural tube closure along the prosencephalon (Pr) and rhombencephalon (Rh) and (J-N) was prominently expressed along the mid sagital prosencephalon from E9.0-E10.5. (L,M') Rostral prosencephalon expression continued into the presumptive olfactory bulb (OB) region. (J-N') Tiki2 was not detected in the fore limb (FL) or hind limb (HL) buds, but was prominent in lateral plate mesoderm (LPM) between the

limb buds. (0,0') Tiki2 expression became more elaborate at E11.5 and was detected in the developing spinal cord (SC) and intermediate mesoderm (IM). Littermate embryos from the early stages were probed with Fgf8 in parallel to control for RNA integrity (data not shown). (P) Northern blotting of total RNAs of adult mouse heart, brain, spleen, lung, skeletal muscle, kidney and testes (Clontech) was performed for the mouse Tiki2 and Gapdh. 
elaborate expression pattern in the intermediate mesoderm and developing spinal cord (Fig. $5 \mathrm{~N}-\mathrm{O}$ ).

We also examined mouse Tiki2 expression in several adult tissues via northern blotting. Transcripts of $6.7 \mathrm{~kb}, 5.0 \mathrm{~kb}$ and $2.2 \mathrm{~kb}$ were detected using the full-length Tiki2 $1.5 \mathrm{~kb}$ cDNA probe. These sizes are consistent with predicted polyadenlylation sites and represented by ESTs from oligo dT-primed libraries. Tiki2 displayed the highest expression in adult heart and testis, followed by the brain, lung and kidney (Fig. 5P). These results are consistent with an earlier report that high Tiki2 expression was detected in the heart and kidney (Zhang, 2012).

\section{Discussion}

\section{Tiki proteins in vertebrates/mammals}

The Tiki family constitutes a new class of Wnt signaling antagonists, operating via proteolytic cleavage of the amino terminus of, and thereby inactivating, Wnt proteins (Zhang et al., 2012). A Tiki homologue is encoded in the genome of the sea anemone Nematostella and of the sponge Amphimedon, suggesting that the Wnt-inhibitory action of Tiki proteins likely evolved early in metazoans before the chordate gene duplication event that generated Tiki1 and Tiki2 (Zhang et al., 2012). Our phylogenetic analysis shows that Tiki1 and Tiki2orthologues are highly conserved among vertebrate and mammalian species, although the Tiki1 gene had been lost in Rodentia. Interestingly the conserved TIKI domain can be traced to prokaryotic TraB proteins, which are negative regulators of sex pheromone signaling in bacteria (Bazan et al., 2013, Sanchez-Pulido and Ponting, 2013). We note that a putative gene product named TRABD represents the third human protein with a distantly related TraB domain. However TRABD shares little sequence similarity with $\mathrm{TIKI} 1$ and TIKI2 and is a predicted cytosolic protein, making it unlikely to participate in Wnt cleavage. We note for clarity that several databases identify TIKI1 as TRABD2A and TIKI2 as TRABD2B.

\section{Tiki expression in the Organizer in chick, rabbit, and mouse embryos}

In amphibian Xenopus laevis embryos Tiki1 expression is restricted to the dorsal side of the embryo during gastrula and neurula stages (Zhang et al., 2012). Specifically, Tiki1 is expressed exclusively in the Organizer at the gastrula stage and becomes restricted afterwards to the prechordal mesoderm and endomesoderm that constitute the "head organizer" (Zhang et al., 2012). The expression pattern of Tiki1 is similar to that of Dkk1 in frogs, and like Dkk1, Tiki1 is required for anterior patterning and head formation (Zhang et al., 2012). The anterior deficiency phenotype as a result of Tiki1 depletion in Xenopus embryos is fully rescued by Dkk1 mRNA injection (Zhang et al., 2012). These findings support the model that inhibition of Wnt signaling by the organizer, through a combination of different molecular strategies, is essential for vertebrate anterior development.

Similar, yet distinct, expression patterns of Tiki1 and Tiki2 in the organizer region in chick, rabbit, and mouse embryos are generally consistent with the above model. Although Tiki1 expression is excluded from the Organizer tissues in the chick, Tiki2 expression is detected in the Organizer in Hensen's node and the forebrain organizer, the prechordal plate. These results suggest that Tiki2, but not Tiki1, has a role in head and forebrain patterning in chick (Table
1). In rabbit embryos, whose early embryogenesis resembles that of humans, Tiki1 expression is restricted to cells of the hypoblast layer underlying Hensen's node and its periphery in the earliest stages of development. Subsequently rabbit Tiki1 expression is detected in the prechordal plate region and in endodermal tissue. Similarly, rabbit Tiki2 is also expressed in the prechordal plate. These results suggest participation of both Tiki1 and Tiki2 in the anterior patterning in rabbits (Table 1).

Mice and other rodents have unique early embryogenesis among mammals in that they develop as an egg cylinder rather than a disc (Arkell and Tam, 2012, Solnica-Krezel and Sepich, 2012, Viebahn, 1999). Somewhat unexpectedly, mice and other rodents appear to have lost the Tiki1 gene. Whether Tiki1 loss is related to the unique embryogenesis of rodents is unclear. Nonetheless, mouse Tiki2 expression is detected in the anterior neural fold and $\mathrm{PcP}$, as observed in chick and rabbit embryos, suggesting a potential role of Tiki2 in anterior patterning in mice (Table 1).

\section{Tiki expression in other aspects of chick, rabbit, and mouse embryogenesis}

Tiki1 showed a dynamic expression pattern during early chick development with gaps in its expression in some stages of development as seen in E2, showing specific tissue expression from E2.5 onwards, such as dorsal neural tube and maxillary bud (Fig 2). Tiki2 was present during somitogenesis, in the presomitic and somitic mesoderm in rabbit, however Tiki2 was not found in the somitic mesoderm in chick embryos. Tiki2 expression was also detected in mouse as a dorsal stripe along the AP axis, similar to the expression pattern found for Tiki1 in chick embryos. In chick embryos, the expression of Tiki2 in the early endoderm and in the AIP is persistent at the early stages of development while the embryo was flattened in a disc shape. On the other hand, rabbit embryos showed an early endoderm expression of Tiki1, with expression following in the PcP and flanking the notochordal plate. Earliest stages expression of Tiki2 can be seen in all the three germ layers in rabbit embryos. Tiki2 is expressed in the developing heart of mouse and chick, but not in rabbit which expressed Tiki1 in the

TABLE 1

\section{SUMMARY OF TIKI1 AND TIKI2 EXPRESSION DURING CHICK, RABBIT AND MOUSE EARLY DEVELOPMENT}

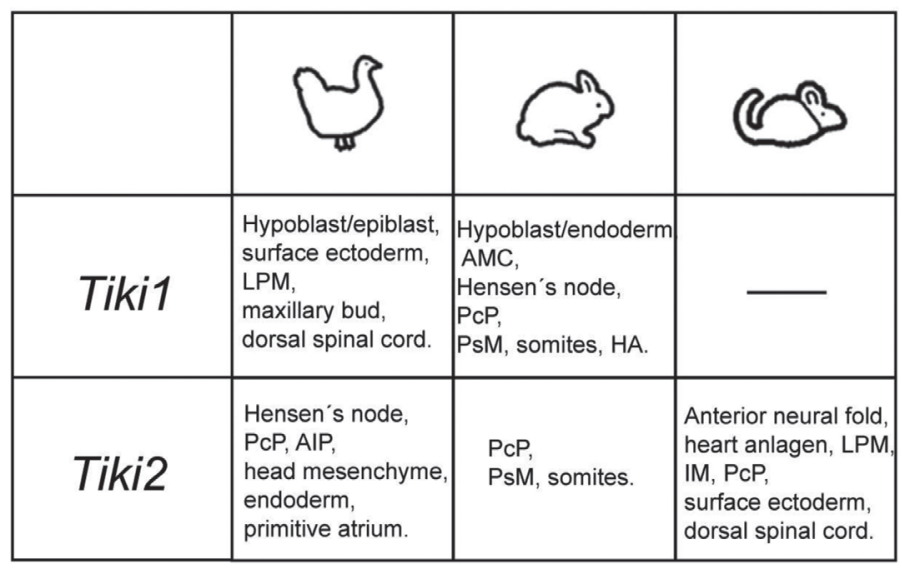

AIP, anterior intestinal portal; AMC, anterior marginal crescent; PsM, presomitic mesoderm; HA heart anlage; PCP, prechordal plate; IM, intermediate mesoderm; LPM, lateral plate mesoderm. 
heart anlage (Table 1). These expression patterns suggest that in rabbits, Tiki1 might be important for early steps of heart induction, while in the mouse and chick, Tiki1/2 expression may be important during the heart looping and for cardiac chamber specification. Inhibition of Wnt signaling is critical for heart induction (Marvin et al., 2001). Moreover, it has been reported that signaling pathways involved in the anteroposterior patterning of the neural ectoderm also influence the cardiac chamber formation (Xavier-Neto et al., 2001).

\section{Variations of a common theme: distinct Wnt antagonists in embryonic patterning}

Several families of Wnt inhibitors exist in vertebrates with different modes of action for the fine tuning of the Wnt pathway (Cruciat and Niehrs, 2013). Such exquisite control is essential for many development processes such as AP patterning. In fact most known families of Wnt antagonists were discovered in the study of the Organizer function in AP patterning in Xenopus, including sFRPs, Cerberus, Dkk1, and Tiki1. The expression and requirement of Dkk1, which binds to and inhibits the Wnt coreceptor LRP6 (Bafico et al., 2001, Glinka et al., 1998, Mao et al., 2001, Semenov et al., 2001), is shared among frogs, zebrafish, and mice (De Robertis and Kuroda, 2004, Niehrs, 2004), supporting the notion that the main role of the head organizer is to antagonize Wnt signaling, which instructs posterior patterning (Petersen and Reddien, 2009). However, there seem to be evolutionary variations of this common theme among vertebrates in terms of the usage and molecular nature of other Wnt antagonists. For example, Cerberus in Xenopus is a multi-valent inhibitor of Wnt, BMP and Nodal pathways and is involved in head development (Belo et al., 2009). Loss of function of Cerberus through morpholino antisense oligo depletion inhibits head formation (Kuroda et al., 2004), while in mouse Cerberus-like does not possess Wnt antagonist activity and its deletion does not affect head formation (Belo et al., 2009). In a similar vein, while we found that Tiki1 in Xenopus is required for head development (Zhang et al., 2012), rodents including mice appear to have lost the Tiki1 gene and thus are different from other vertebrates/mammals examined, which have both Tiki1 and Tiki2 genes. Furthermore, while chick and rabbit embryos exhibit Organizer Tiki expression like Xenopusembryos, Tiki2, but not Tiki1, shows Organizer-specific expression in chick while Tiki1 and Tiki2 share co-expression in the Organizer in rabbits. These variations may reflect some stochastic events during evolution or unique aspects of early embryogenesis in different vertebrates while preserving the fundamental function of the head organizer in antagonizing Wnt signaling.

\section{Tiki expression in adult tissues in human and mice}

In human the TIKI1/TRABD2A mRNA is detected in adult tissues including the small intestine, colon, lung and ovary while TIKI2/TRABD2B is detected in the kidney, heart, adipose tissue, and gallbladder (www.proteinatlas.org). This tissue distribution of human TIKI2 is in agreement to that previously reported for mouse Tiki2 (Zhang, 2012), whose expression in fat is regulated by diet (Zhang, 2012). Thus TIKIgenes may have dynamic expression in adult tissues under physiological and pathological conditions. Indeed database search shows that expression of TIKI1 and/or TIKI2 is altered in a variety of cancers and disease tissues (Supplemental Table 1). Indeed consistent with our findings that TIKI2 expression is downregulated in osteosarcoma (Supplemental Table 1), forced expression of TIKI2 inhibits osteosarcoma cell growth and cancerous behaviors in culture and in mouse xenografts (Li et al., 2014). Therefore like DKK1 and SOST, which is a Wnt antagonist mutated in skeletal disease sclerosteosis (Baron and Kneissel, 2013), TIKI1 and TIKI2 may be involved in human pathogenesis.

\section{Materials and Methods}

\section{Plasmid construction of Tiki probes}

Using available genomic and EST sequences, primers were made to amplify full-length TikicDNAs (or as much as possible) for chicken (Gallus gallus), rabbit (Oryctolagus cuniculus) and mouse (Mus musculus) Tiki genes. Full-length vertebrate Tiki proteins are encoded by seven exons, however the sequence of the first and/or the last exon was not always available due to promoter high GC content or low sequence homology. A chicken Tiki1 partial cDNA probe (1073bp, ChT1exon2FAGCTGAACTCCTTCCTGTGG and ChT1exon6R CTCCTTCAGGGTATGCAACG) and a chicken Tiki2 full length cDNA probe (1614bp, ChT2exon1F GGGATGCAACTCAACCTGAC and ChT2exon7R CTCTATTCCAAGGGATTGCAC) were generated using RT-PCR from RNAs of stage HH21 White Leghorn chick embryos and TOPO cloned into the $\mathrm{PCRII-TOPO}$ vector (Invitrogen). Using similar methods, a fulllength RabbitTiki1 cDNA(1553 bp, RaT1exon1FCCGTTGTCGGGAGGATG and RaT1exon7R GCCTGGCTCCTCAGTCATTC) and a partial Rabbit Tiki2 cDNA (1471 bp, RaT2exon2F CCTGAACTCCTTCCTGTGGAand RaT2exon7R GTGGCCGAGGTCAGGAG) were amplified via RT-PCR of RNAs from adult New Zealand White rabbit intestine and kidney, respectively, and TOPO cloned into the pCRII-TOPO vector. A full-length mouse Tiki2 cDNA (1517 bp MoT2exon1F TAACTCGAGCCACCATGCACGCCGCCCTGGC and MoT2exon7R TAATCTAGATCAGGAAGGCCCAAGGCTGTG) was amplified via RT-PCR of RNAs from cultured mouse $L$ cells (ATCC CRL2648) and cloned into the pCS2+ expression vector using Xhol/Xbal sites. Antisense probes were made using SP6 or T7 polymerase from linearized plasmid vectors. Mouse Tiki2 cDNA was also used to make a ${ }^{32} \mathrm{P}$ random labeld probe (Rediprime II, Amersham) for detecting Tiki2 transcripts from a Clontech northern blot containing total RNA from adult mouse tissues. The northern blot was reprobed with a Gapdh probe (448 bp, GapdhF GCCAAAAGGGTCATCATCTC and GapdhR CCTGCTTCACCACCTTCTTG) as a control.

\section{Chick, rabbit and mouse embryos}

Fertized chick eggs were incubated at $37^{\circ} \mathrm{C}$ and staged according to Hamburger and Hamilton (1951). Mated female rabbits (New Zealand White) were purchased from a commercial breeder (ZIKA, Germany) and sacrificed according to German animal law. Embryos from timed pregnancies were dissected from uteri in PBS at room temperature and fixed for in situ hybridization in $4 \%$ PFA at $4^{\circ} \mathrm{C}$ overnight. Embryos were staged according to Blum et al., (2007). Mouse embryos were obtained from timed pregant C57BL/6J females as previously described (Adamska et al., 2003). Noon of the day when the vaginal plug was found was considered to be E0.5.

\section{Whole mount in situ hybridization}

Whole-mount in situ hybridization using digoxygenin-labeled riboprobes was performed following standard protocols or as described in (Brito et al., 2008). Chick embryos from stage $\mathrm{HH} 4$ to $\mathrm{HH} 20-21$ were fixed in $4 \%$ formaldehyde at $4^{\circ} \mathrm{C}$ overnight, and then dehydrated in a methanol series.

After in situ hybridization, chick embryos were dehydrated in ethano series, cleared in butanol and embedded in paraffin wax. Cross sections at 10 or $20 \mu \mathrm{m}$ were performed to show internal structures. Rabbit embryo histology was performed as described (Fischer et al., 2002).

\section{Phylogeny analysis and protein sequences}

The Tiki genes tree was clustered using a Neighbor-Joining phylogenetic method (Mega5 software). The phylogenetic analysis of TIKI proteins was tested using a bootstrap method and resampled at least 1000 times. The result is a percentage of times that a particular grouping was on each side 
of a branch without concerning the subgrouping. TIKI protein sequences were derived from full-length NCBI accessions and genomic sequences. Chicken and Rabbit Tiki1/2 ESTs were independently cloned for use as in situ probes. Human [Homo sapiens] TIKI1:AFN02881.1 and NP_001263982.1, TIKI2: AFN02882.1 and NP_001181915.1; Macaque [Macaca mulatta] Tiki1:EHH22275.1,Tiki2:XP_001101255.2; Rabbit[Oryctolagus cuniculus] Tiki1: based on genomic sequence and XP_002709727.1 (missing exon 3), Tiki2: based on genomic sequence for exons2-7, exon1 was inferred from Human/Mouse; Mouse [Mus musculus] Tiki2: NP_001079018.1; Rat [Rattus norvegicus] Tiki2: based on genomic sequence and XP_001072500.2; Guinea Pig [Cavia porcellus] Tiki2: based on genomic sequence and XP_003461517.1; Squirrel [Ictidomys tridecemlineatus] Tiki2: based on genomic sequence and XP_005318067.1; Chicken [Gallus gallus] Tiki1: XP_003643097.2, Tiki2: XP_422458.4; Xenopus [Xenopus (Silurana) tropicalis] Tiki1: AFN02883.1 and NP_001269420.1, Tiki2: AFN02884.1 and PODJQ9.1; Cnidaria [Nematostella vectensis] Tiki: AFN02888.1 and A7RX69.2. The identity between species was determined by GeneCode software.

\section{Acknowledgements}

The authors wish to thank Anna Iwanska and Fabio Zuim for technical assistance. AHR, NGA, JMB, JGA were funded by the Brazilian research agencies CNPq and FAPERJ. KF was supported by a Margarete-vonWrangell fellowship, funded by the European Social Fund and by the Ministry Of Science, Research and the Arts in Baden-Württemberg. XH is an endowed research chair of Boston Children's Hospital (BCH) and acknowledges support by NIH (RO1 GM057603 and R01 AR060359) and $\mathrm{BCH}$ Intellectual and Developmental Disabilities Research Center (P30 HD-18655).

\section{References}

ADAMSKA, M., MACDONALD, B.T. and MEISLER, M.H. (2003). Doubleridge, a mouse mutant with defective compaction of the apical ectodermal ridge and normal dorsal-ventral patterning of the limb. Dev Biol 255: 350-362.

ARKELL, R.M. and TAM, P.P. (2012). Initiating head development in mouse embryos: integrating signalling and transcriptional activity. Open Biol 2: 120030.

BAFICO, A., LIU, G., YANIV, A., GAZIT, A. and AARONSON, S.A. (2001). Novel mechanism of Wnt signalling inhibition mediated by Dickkopf-1 interaction with LRP6/Arrow. Nat Cell Biol 3: 683-686.

BARON, R. and KNEISSEL, M. (2013). WNT signaling in bone homeostasis and disease: from human mutations to treatments. Nat Med 19: 179-192.

BARRETT, T., WILHITE, S.E., LEDOUX, P., EVANGELISTA, C., KIM, I.F., TOMASHEVSKY, M., MARSHALL, K.A., PHILLIPPY, K.H., SHERMAN, P.M., HOLKO, M. et al., (2013). NCBI GEO: archive for functional genomics data sets--update. Nucleic Acids Res 41: D991-D995.

BAZAN, J.F., MACDONALD, B.T. and HE, X. (2013). The TIKI/TraB/PrgY family: a common protease fold for cell signaling from bacteria to metazoa? Dev Cell 25: 225-227.

BELO, J.A., SILVA, A.C., BORGES, A.C., FILIPE, M., BENTO, M., GONCALVES, L., VITORINO, M., SALGUEIRO, A.M., TEXEIRA, V., TAVARES, A.T. et al., (2009). Generating asymmetries in the early vertebrate embryo: the role of the Cerberuslike family. Int J Dev Biol 53: 1399-1407.

BENTON, M.J. and DONOGHUE, P.C. (2007). Paleontological evidence to date the tree of life. Mol Biol Evol 24: 26-53.

BLUM, M., ANDRE, P., MUDERS, K., SCHWEICKERT, A., FISCHER, A., BITZER, E., BOGUSCH, S., BEYER, T., VAN STRAATEN, H.W. and VIEBAHN, C. (2007). Ciliation and gene expression distinguish between node and posterior notochord in the mammalian embryo. Differentiation 75: 133-146.

BRITO, J.M., TEILLET, M.A. and LEDOUARIN, N.M. (2008). Induction of mirror-image supernumerary jaws in chicken mandibular mesenchyme by Sonic Hedgehogproducing cells. Development 135: 2311-2319.

CLEVERS, H. and NUSSE, R. (2012). Wnt/beta-catenin signaling and disease. Cell 149: 1192-1205.
CRUCIAT, C.M. and NIEHRS, C. (2013). Secreted and transmembrane wnt inhibitors and activators. Cold Spring Harb Perspect Biol 5: a015081.

DE ROBERTIS, E.M. and KURODA, H. (2004). Dorsal-ventral patterning and neural induction in Xenopus embryos. Annu Rev Cell Dev Biol 20: 285-308.

FISCHER, A., VIEBAHN, C. and BLUM, M. (2002). FGF8 acts as a right determinant during establishment of the left-right axis in the rabbit. Curr Biol 12: 1807-1816.

GLINKA, A., WU, W., DELIUS, H., MONAGHAN, A.P., BLUMENSTOCK, C. and NIEHRS, C. (1998). Dickkopf-1 is a member of a new family of secreted proteins and functions in head induction. Nature 391: 357-362.

HAMBURGER, V. and HAMILTON, H.L. (1951). A series of normal stages in the development of the chick embryo. J Morphol 88: 49-92.

IDKOWIAK, J., WEISHEIT, G. and VIEBAHN, C. (2004). Polarity in the rabbit embryo. Semin Cell Dev Biol 15: 607-617.

KURODA, H., WESSELY, O. and DE ROBERTIS, E.M. (2004). Neural induction in Xenopus: requirement for ectodermal and endomesodermal signals via Chordin, Noggin, beta-Catenin, and Cerberus. PLoS Biol 2: E92.

LI, R., LIU, J., WU, H., LIU, L., WANG, L. and ZHANG, S. (2014). TIKI2 suppresses growth of osteosarcoma by targeting Wnt/beta-catenin pathway. Mol Cell Biochem. 392: 109-16.

MACDONALD, B.T., TAMAI, K. and HE, X. (2009). Wnt/beta-catenin signaling: components, mechanisms, and diseases. Dev Cell 17: 9-26.

MAO, B., WU, W., LI, Y., HOPPE, D., STANNEK, P., GLINKA, A. and NIEHRS, C. (2001). LDL-receptor-related protein 6 is a receptor for Dickkopf proteins. Nature 411: 321-325.

MARVIN, M.J., DI ROCCO, G., GARDINER, A., BUSH, S.M. and LASSAR, A.B. (2001). Inhibition of Wnt activity induces heart formation from posterior mesoderm. Genes Dev 15: 316-327.

NIEHRS, C. (2004). Regionally specific induction by the Spemann-Mangold organizer Nat Rev Genet 5: 425-434.

PARKINSON, H., SARKANS, U., KOLESNIKOV, N., ABEYGUNAWARDENA, N., BURDETT, T., DYLAG, M., EMAM, I., FARNE, A., HASTINGS, E., HOLLOWAY, E. et al., (2011). ArrayExpress update--an archive of microarray and highthroughput sequencing-based functional genomics experiments. Nucleic Acids Res 39: D1002-D1004.

PETERSEN, C.P. and REDDIEN, P.W. (2009). Wnt signaling and the polarity of the primary body axis. Cell 139: 1056-1068.

PICCALUGA, P.P., AGOSTINELLI, C., CALIFANO, A., CARBONE, A., FANTONI, L. FERRARI, S., GAZZOLA, A., GLOGHINI, A., RIGHI, S., ROSSI, M. et al., (2007) Gene expression analysis of angioimmunoblastic lymphoma indicates derivation from T follicular helper cells and vascular endothelial growth factor deregulation. Cancer Res 67: 10703-10710.

RHODES, D.R., KALYANA-SUNDARAM, S., MAHAVISNO, V., VARAMBALLY, R., YU, J., BRIGGS, B.B., BARRETTE, T.R., ANSTET, M.J., KINCEAD-BEAL, C. KULKARNI, P. et al., (2007). Oncomine 3.0: genes, pathways, and networks in a collection of 18,000 cancer gene expression profiles. Neoplasia 9: 166-180.

SAITOU, N. and NEI, M. (1987). The neighbor-joining method: a new method for reconstructing phylogenetic trees. Mol Biol Evol 4: 406-425.

SANCHEZ-PULIDO, L. and PONTING, C.P. (2013). Tiki, at the head of a new superfamily of enzymes. Bioinformatics 29: 2371-2374.

SEMENOV, M.V., TAMAI, K., BROTT, B.K., KUHL, M., SOKOL, S. and HE, X. (2001) Head inducer Dickkopf-1 is a ligand for Wnt coreceptor LRP6. Curr Biol11: 951-961.

SOLNICA-KREZEL, L. and SEPICH, D.S. (2012). Gastrulation: making and shaping germ layers. Annu Rev Cell Dev Biol 28: 687-717.

VIEBAHN, C. (1999). The anterior margin of the mammalian gastrula: comparative and phylogenetic aspects of its role in axis formation and head induction. Curr Top Dev Biol 46: 63-103.

XAVIER-NETO, J., ROSENTHAL, N., SILVA, F.A., MATOS, T.G., HOCHGREB, T. and LINHARES, V.L. (2001). Retinoid signaling and cardiac anteroposterior segmentation. Genesis 31: 97-104

ZHANG, R. (2012). Hkat, a novel nutritionally regulated transmembrane protein in adipose tissues. Sci Rep 2: 825.

ZHANG, X., ABREU, J.G., YOKOTA, C., MACDONALD, B.T., SINGH, S., COBURN, K.L., CHEONG, S.M., ZHANG, M.M., YE, Q.Z., HANG, H.C. et al., (2012). Tiki1 is required for head formation via Wnt cleavage-oxidation and inactivation. Cell 149: 1565-1577. 


\section{Further Related Reading, published previously in the Int. J. Dev. Biol.}

Sox7 in vascular development: review, insights and potential mechanisms Jeanette J. Wat and Margaret J. Wat.

Int. J. Dev. Biol. (2014) 58: 1-8.

Expression of Shisa2, a modulator of both Wnt and Fgf signaling, in the chick embryo Thomas A. Hedge and Ivor Mason

Int. J. Dev. Biol. (2008) 52: 81-85 http://www.intjdevbiol.com/web/paper/072355th.

Retinoic acid metabolizing factor XCyp26c is specifically expressed in neuroectoderm and regulates anterior neural patterning in Xenopus laevis

Misaki Tanibe, Tatsuo Michiue, Akira Yukita, Hiroki Danno, Masayuki Ikuzawa, Shoichi Ishiura and Makoto Asashima

Int. J. Dev. Biol. (2008) 52: 893-901 - http://www.intjdevbiol.com/web/paper/082683mt

Systematic screening for genes specifically expressed in the anterior neuroectoderm during early Xenopus development

Noriyuki Takahashi, Naoko Tochimoto, Shin-Ya Ohmori, Hiroshi Mamada, Mari Itoh, Masako Inamori, Jun Shinga, Shin-Ichi Osada and Masanori Taira

Int. J. Dev. Biol. (2005) 49: 939-951.

Defects of the body plan of mutant embryos lacking Lim1, Otx2 or Hnf3beta activity. S J Kinder, T E Tsang, S L Ang, R R Behringer and P P Tam Int. J. Dev. Biol. (2001) 45: 347-355.

5 yr ISI Impact Factor $(2011)=2.959$
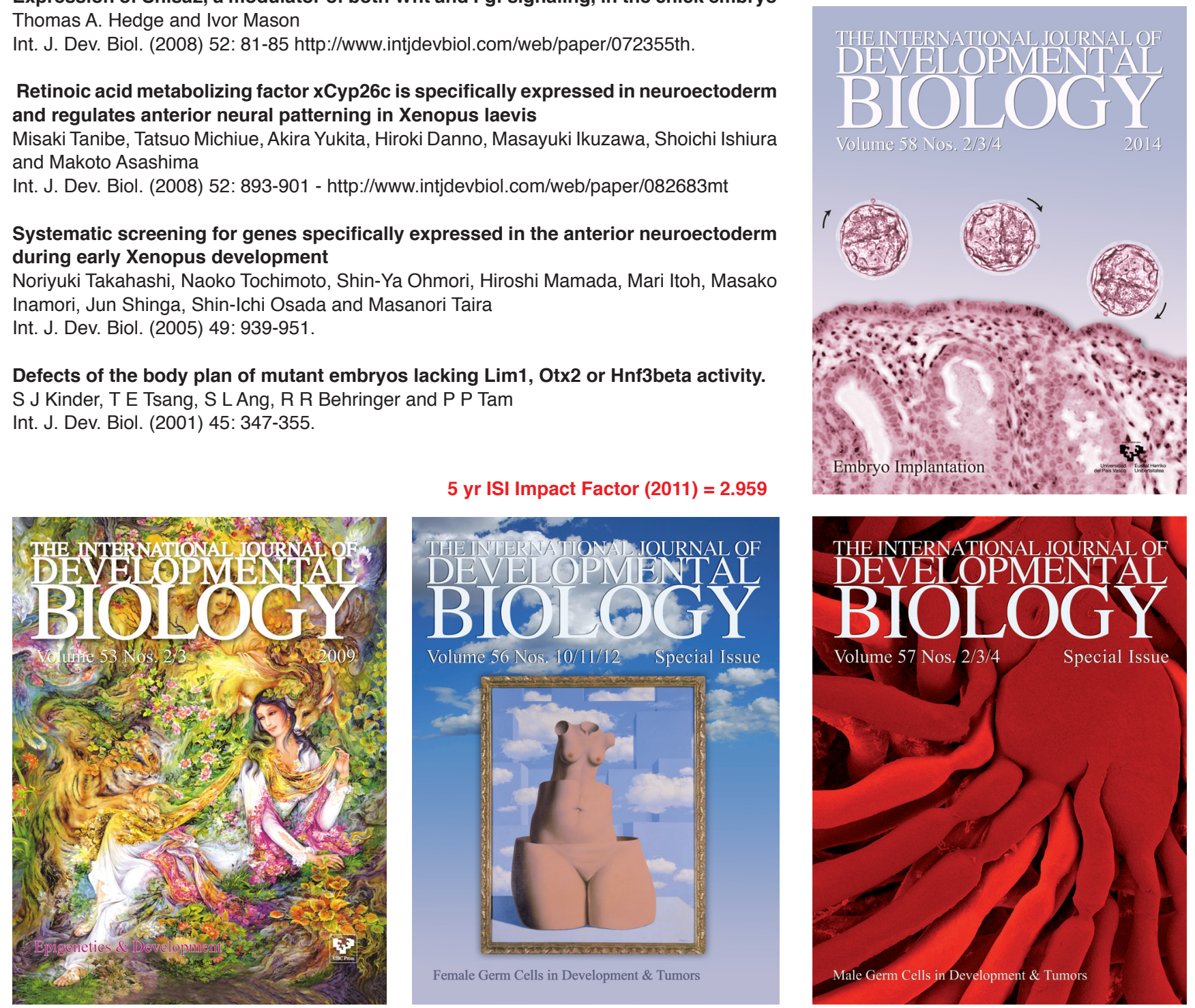

Volume 57 Nos. 2/3/4 Special Issue

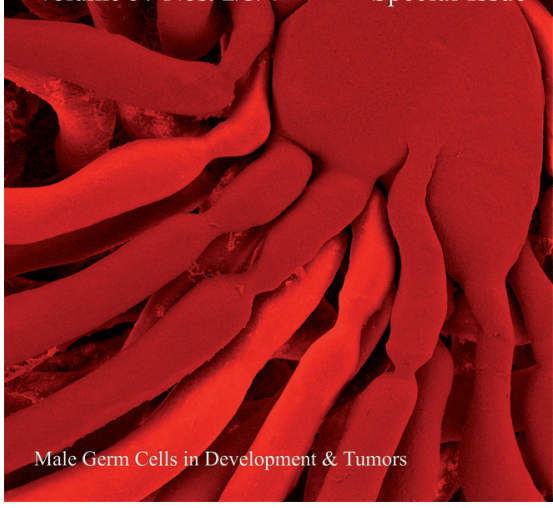

